\title{
Periodismo y humanidades en César Vallejo
}

\author{
Pedro J. Granados' \\ https://orcid.org/0000-0001-8359-397X \\ I - Universidad Nacional Mayor de San Marcos (NMSM) \\ Lima, Peru
}

Resumen: Se estudió el periodismo de César Vallejo, sus crónicas, en relación con varias nociones de las humanidades que se proponen aquí; humanidades en tanto libros, pueblos, narrativas o post-antropocentrismo. No menos, en la vinculación de aquéllas con el neo realismo (Meillassoux, Gabriel, Harman, etc.); por cuanto, periodista y filósofos, finalmente enarbolan el giro ontológico. También este ensayo se propuso elaborar, aunque muy inicial, una taxonomía cualitativa de las crónicas; es decir, una no temática o meramente cronológica. El resultado fue, creemos, confirmar la actualidad e incluso virtualidad - futuridad - de César Vallejo como periodista.

Palabras clave: humanidades y periodismo; crónicas de César Vallejo; nuevo realismo.

Abstract: Journalism and humanities in César Vallejo - The journalism of César Vallejo, his chronicles, was studied in relation to several notions of the humanities proposed here; humanities as books, peoples, narratives or post-anthropocentrism. No less, in linking them with Neo Realism (Maillassoux, Gabriel, Harman, etc.); in as much, journalist and philosophers, finally raise the ontological turn. Also this essay was proposed to elaborate, although very initial, a qualitative taxonomy of the chronicles; that is, a non-thematic or merely chronological one. The result was, we believe, to confirm the news and even virtuality - futurity - of César Vallejo as a journalist.

Keywords: humanities and journalism; chronicles of César Vallejo; new realismo.

\section{Introducción}

En el presente artículo enmarcaremos algunas de las crónicas de César Vallejo: "Vallejo explicado por el propio Vallejo" (PUCCINELLI, 2002, p. XVI), publicadas entre 1918 a 1937. En específico, aquellas que versan, según David Sobrevilla, sobre el tema incaico (GONZÁLEZ MONTES, 1999, p.238) o, con mayor amplitud, sobre el que podemos 
denominar y vamos a preferir: el tema peruano. Es decir, uno que incluye y marcha en paralelo al anterior en tanto y en cuanto la supuesta tardía eclosión de ambos temas (1931) en su obra cronística. Enmarcar y adjudicar un sentido a estas crónicas de acuerdo con ciertas nociones de las humanidades gravitando allí (humanidades entendidas como libros, pueblos, narrativas o post-antropocentrismo). Aunque cada una de aquellas nociones sea distinta una de la otra, Vallejo en su obra periodística - no menos, en la poética, narrativa y teatral -, y más notoriamente desde la "prosa posmodernista que escribió los últimos 13 años de su vida" (CHANG, 1992, p.11), sin confundirlas, las conjuga todas. Es decir, el tema incaico va a modificarse en el tiempo conforme se tamice y coincidan sobre aquél una o varias de aquellas cuatro nociones de las humanidades mencionadas más arriba. En este sentido, nuestro trabajo consistirá en apenas una muestra, respecto al total del corpus cronístico vallejiano, sobre cómo evolucionarían o se modificarían otros temas o motivos en sus crónicas y, por lo tanto, luego pueda abordarse una taxonomía más completa y exhaustiva - como desde dentro, y no desde una óptica meramente lineal o cronológica - del total de las mismas.

Embrión de taxonomía de las crónicas de César Vallejo, nuestro trabajo, que asimismo intenta aportar nuevos enfoques teóricos, distintos a los usuales: temático-ideológicos o estilístico-filológicos, que hasta el día de hoy monopolizan su recepción. Entre aquéllos, señalar aquí algunas significativas afinidades entre la obra del autor peruano y las propuestas ontológicas del reciente nuevo realismo (Meillassoux, Gabriel, Harman, Ferraris, entre otros). Relaciones conceptuales, entre César Vallejo y el nuevo realismo, las cuales constituyen una primicia en sí mismas. Algo tentativo, por cierto, pero luego de las ecualizaciones pertinentes, capaz de entablar un diálogo estimulante y, esperamos, no menos productivo en torno a la lectura de la obra y, en concreto, de la extensa labor periodística del peruano.

\section{Libros, pueblos, narrativas o post-antropocentrismo}

Más allá de los formatos o técnicas, de antemano todos leemos y escribimos desde un lugar (social, cultural, de género, retórico, etc.); por ello, resulta fundamental distinguir las nociones de las Humanidades que nos orientan $y$, veremos en seguida, orientaron también a César Vallejo. Las nociones sobre las humanidades en cuanto libros, pueblos, narrativas o post-antropocentrismo se yuxtaponen o dialogan en nuestro mundo contemporáneo. Aunque, según sea el caso, una de ellas constituya la concepción dominante o preeminente. Por este motivo, resulta lógico cunda el desconcierto. Dichas concepciones son el resultado de específicos procesos históricos, culturales, científicos y políticos; aunque todas ellas coexisten y se precisa de un análisis y crítica detenidos para distinguirlas unas de las otras. Humanidades en tanto: 


\subsection{Libros o canon occidental (H1)}

Obras de arte y literarias que han pasado a constituir la denominada alta cultura en la civilización occidental. Ideológicamente clasista y socialmente elitista. Para sus detractores, multiculturalistas, aquel canon no representa el punto de vista de muchos otros en las sociedades contemporáneas. Idea esencialista o autónoma de la literatura. Defensor, Harold Bloom.

\subsection{Pueblos o culturas $(\mathrm{H} 2)$}

Humanidades implica visibilidad de pueblos y minorías en plural: mujeres, indígenas, minorías sexuales. Idea no esencialista y sí, más bien, post-autónoma de la literatura. La cual no se halla o se define ya más por la intención del autor ni por la supuesta valía del texto en sí mismo, sino por lo que decida el público o el receptor. Interpretaciones alternativas del mundo. Multiculturalismo. Doña Bárbara, por ejemplo: "no está determinada por la concepción que los naturalistas decimonónicos tenían de la naturaleza, sino por mitos sobre el origen cultural y la autoridad misma. Por lo tanto, desde los años veinte [años también de Trilce], tenemos un nuevo discurso hegemónico: antropológico. Ya no darwineano, sino abierto a lo irracional" (GONZÁLEZ ECHEVARRÍA, 2012, p. 207).

\subsection{Narrativas o prosopopeya $(\mathrm{H} 3)$}

No existen hechos, sino sólo interpretaciones de estos (NIETZSCHE, 2008, p. 60). El lenguaje remite solo a otros juegos de lenguaje (WITTGENSTEIN, 2017, p. 329). Giro linguístico. El sujeto no existe previo a su prosopopeya; es decir, a lo que - por ejemplo, como en las fábulas de Esopo - ocurre cuando se nos representa un zorro que habla. Autobiografía sólo como escritura (Borges y yo) ${ }^{1}$. Posmodernidad. Por lo tanto, todo no es más que lenguaje o todo no es más que literatura: “El origen, el yo y la historia del yo son figuras literarias de la imaginación literaria europea, tanto como productos de la investigación científica" (GONZÁLEZ ECHEVARRÍA, 2012, p.165). Entonces, hoy no consiste en preguntarse, como antes, qué tanto de realidad existe en la ficción, sino qué tanto de ésta existe en la realidad (PIGLIA, 2000, p. 28). "Somos contos contando contos, nada" (PESSOA, 1994, p.168).

1 Con el ejemplo de "Borges y yo", en referencia al "giro lingüístico", aludimos a que de acuerdo a este último: "la realidad no es una referencia objetiva, externa al discurso, sino que siempre es construida en y por el lenguaje" (CHARTIER, p. 67). 


\subsection{Post-antropocentrismo o simetría $(\mathrm{H} 4)$}

En sus dos acepciones:

\subsubsection{Multinaturalismo}

Giro animal: "Se afirma la unidad ('universalidad') de un espíritu cósmico versus la diversidad (o 'particularidad') de los cuerpos naturales" (RIZO-PATRÓN, 2013, p.196) ${ }^{2}$. Importancia del mito: "Todo mito es por naturaleza una traducción [...] se sitúa, no en una lengua y en una cultura o subcultura, sino en el punto de articulación de éstas con otras lenguas y otras culturas. El mito no es nunca de su lengua, es una perspectiva sobre otra lengua" (VIVEIROS DE CASTRO, 2010, p. 223).

\subsubsection{Post-humanismo}

En el contexto de la globalización, y a diferencia de las humanidades a modo de pueblos o culturas (Multiculturalismo), el Post-humanismo aparece vinculado a la lógica de la homogeneización. Si, desde la cibernética, la capacidad de comunicación e información viene a constituir la definición del ser; entonces, máquinas y humanos se hacen simétricos e intercambiables (cyborgs). Así como, desde la biotecnología, se va de individuos complejos a somáticos.

Hemos abreviado con $\mathrm{H} 1, \mathrm{H} 2, \mathrm{H} 3$ y $\mathrm{H} 4$, cada una de aquellas descripciones de las diferentes nociones de las humanidades aquí ventiladas; en lo básico, no sólo por el ahorro de espacio, sino también para facilitar su manejo.

\section{Tamizados del tema peruano a través de H1, H2, H3 y H4}

\subsection{Configuración previa}

Según el Índice Onomástico de la edición de las crónicas de César Vallejo (VALLEJO, 2002, t. II, p.1075-1119)33, debida a Jorge Puccinelli, los temas inca (Inca, Inca Garcilaso, Incas) y Perú se despliegan, ambos, paralelamente, desde la página 886 y la página 889, respectivamente ${ }^{4}$; dato que los hace casi coincidir a los dos temas en la fecha de 1931; que no es un año cualquiera, sino el del ingreso del autor al partido comunista español ${ }^{5}$. Sin embargo, el tema Perú se desplegó en las crónicas de Vallejo, antes y como una constante. Desde la primera, publicada en La Reforma de Trujillo, Con el Conde de Lemos (1918),

2 Se basa en el perspectivismo amerindio: "Ios indios americanos imaginan una continuidad metafísica y una discontinuidad física entre los seres cósmicos" (RIZO-PATRÓN, [2013], p.196).

3 "publicadas entre 1918 y 1938 conforman un corpus de cerca de 250, de las cuales 178 fueron escritas entre 1926 y 1929 en un promedio de dos semanalmente" (CHANG RODRíGUEZ, 1982, p 12).

4 El tema incaico en 1931 (La crónica incaica); el tema Perú en 1933 (Un gran reportaje político. ¿Qué pasa en América del Sur? En el país de los incas).

5 "Vallejo tuvo expresiones duras para el movimiento hacia el cual abrigó por muchos años un sentimiento ambivalente y contradictorio [...] Al ocuparse de 'Los doctores del marxismo' [El arte y la revolución], Vallejo fue claro al expresar su independencia de criterio y libertad artística" (CHANG RODRÍGUEZ, 1982, p. 17-18) 
en referencia a su admirado Abraham Valdelomar y la revista Colónida; y, asimismo, desde su inicial crónica europea, En Montmatre (1925). Tema Perú, pues, ventilado sin pausa hasta el año 1927 (Los escollos de siempre); sin embargo, lugar donde elabora un manifiesto fundamental en el que destaca la antítesis sensibilidad/voluntad, sobre la cual volveremos: "La indigenización es acto de sensibilidad indígena y no de voluntad indigenista. La obra indígena es acto inocente y fatal del creador político o artístico, y no es acto malicioso, querido y convencional de cualquier vecino" (VALLEJO, 2002, t. I, p. 496).

En consecuencia, aquello del "incaísmo final del poeta" ${ }^{6}$, nos limitaría a ventilar sólo las, más bien pocas, crónicas de 1936 y 1937 . El Perú estuvo siempre presente en las crónicas vallejianas; aunque, como se verá, y según se focalicen allí H1, H2, H3 o H4, de un modo distinto. Humanidades entendidas, en lo fundamental, no en tanto temas, sino en cuanto nociones abarcantes o, según Markus Gabriel, destacado representante del nuevo realismo ${ }^{7}$ : pluralismo ontológico o, sin que podamos reducirlos a uno solo, campos de sentido. Todo esto, sin soslayar la complejidad inherente a la propia escritura vallejiana; en particular, aquella motivada por su ideal poetológico: "El artículo que solo toca a las masas es un artículo inferior. Si solo toca a las élites se acusa superior. Si toca a las masas y a las élites, se acusa genial, insuperable" (VALLEJO, 2002, t.II, p. 1067). A lo que debemos sumar algo que añade César Lévano: "Notable es la variedad sobre todo de sus crónicas escritas desde Europa, cuyo carácter misceláneo es como un escaparate de novedades [incluso icónicamente, desde el caleidoscópico sumario que las precede ${ }^{8}$ ], en las cuales suele atisbar el futuro en germen. Su visión es dialéctica, ve los conflictos

6 Sobrevilla rechaza tres de las explicaciones más extendidas acerca del incaísmo final del poeta y señala que cuando éste en La piedra cansada recrea la temática imperial no lo hace pensando en revitalizar la 'raza' autóctona, tampoco para escapar al colapso inminente de la República española, ni para revivir el dormido instinto religioso actuante en etapas previas. Lo que buscaba era "examinar dicho pasado desde la perspectiva de su posición marxista: denunciar en él sus injusticias (no lo idealiza en absoluto)... y mostrar que la historia consiste en el proceso de humanización y de posibilitación de un amor universal, que su agente verdadero es el pueblo y sus opositores, las distintas formas injustas de organización social, la guerra y la religión" (GONZÁLEZ MONTES, 1994, p. 238)

7 "Lo que todos los pensadores que se identifican con el nuevo realismo tienen en común es el rechazo a la desesperanzadora visión generalizada según la cual no podemos conocer cómo son las cosas en sí mismas porque para poder tener acceso a ellas necesitaríamos construir, siguiendo la metáfora de Putnam, una interface. Denominemos a esta visión el constructivismo. Por lo menos ese es el nombre que le ha dado Paul Boghossian, mientras que Quentin Meillassoux en Francia ha sugerido Ilamarlo correlacionismo y Maurizio Ferraris en Italia habla de la falacia trascendental, es decir, la confusión de la ontología (aquello que es) con la epistemología (aquello que sabemos) [...] La visión de la que se aleja el nuevo realismo es este tipo de constructivismo, por lo que la discusión gira alrededor de la pregunta de cómo ser realistas posmetafísicos [...] Ahora bien, esto no debe llevarnos a pensar que debemos abandonar la distinción entre realidad y apariencia y, por lo tanto, el concepto de verdad... La metafísica ha fallado como una teoría de la totalidad, pero eso no significa que no haya teorías exitosas o que seamos incapaces de conocer cómo son las cosas por sí mismas [imposibilidad representada aquí por H3]" (GABRIEL, 2016, p. 165)

8 No está demás traer a consideración, aquí, lo que postula César Vallejo sobre la puesta teatral: una "escena cerebro", en paralelo y simultánea y a vista del público, de la escenificación propiamente dicha (Notas sobre el nuevo teatro, Vallejo, 1999). El sumario, de la crónica vallejiana, actuaría a modo de escena cerebro, caleidoscopio con múltiples posibilidades de resolución o narrativas $(\mathrm{H} 3)$; con sólo alguna de ellas, entre otras posibles, siendo desarrollada por el narrador. En este sentido, la intermedialidad del autor de Trilce, respecto a su lector y/o observador: "aprovecha sobre todo la contaminación y la exclusión, menos la condensación" (HELBO, 2012, p. 38). 
y su arribo al futuro"; y puntualiza, más bien de un modo semiótico, Enrique Ballón: "la escritura poetológica de las crónicas de Vallejo es, respecto de su escritura artística (poesía, narración, teatro), un bastidor con intersticios: un bastidor como el usado en el antiguo teatro griego, no para esconder sino para ayudar a leer alternadamente [...] en digresión, en flexión conceptual semiótica, en reflexión" (BALLÓN, 1982, p. 93). Sin más, por ahora, pasemos a nuestros tamizados.

\subsection{Tamizados}

La idea de un canon occidental [H1] está presente en toda la obra de César Vallejo; mejor dicho, la atraviesa transversalmente desde el inicio hasta el fin. Aunque, para ceñirnos a sus crónicas - y no, por ejemplo, a su primer poemario, Los heraldos negros (1918) donde rinde culto todavía al Modernismo y, entre otros, a la figura de Rubén Darío ${ }^{9}$-, aquello resulta evidente y así ha sido señalado por la crítica ${ }^{10}$. Crónicas las de esta primera etapa, donde encontramos, sobre todo: "sus intermitentes declaraciones estéticas, sus juicios sobre escritores y artistas coetáneos y contemporáneos, sus gustos, sus aversiones, lo que Alfonso Reyes Ilamaría sus simpatías y diferencias literarias" (PUCCINELLI, 2002, p. XV) [H1]. Sin embargo, y a este respecto, el mismo Puccinelli destaque un matiz que nos adentra ya en $\mathrm{H} 2$ :

En esta primera etapa que corresponde principalmente a sus artículos, crónicas y entrevistas publicadas en El Norte [1923 a 1930], Vallejo revela tener muy presente a su público fraterno de la Bohemia de Trujillo [H2], destinatario de sus crónicas, cuyo lenguaje generacional de los primeros días todavía mantiene, recamado con palabras y frases de Trilce y aun de Heraldos negros (PUCCINELLI, 2002, p. XXXII).

Es decir, desde una mirada filológica o estilística [H1], Vallejo adoptaría un estilo particular - cuando publica en El Norte - obedeciendo a una noción de las Humanidades como pueblos [H2]. Tanto como, desde el año 1925, cuando comienza a trabajar en los Grandes Periódicos Iberoamericanos y es corresponsal de Mundial y de otras revistas de

9 Aunque en sus crónicas prevalezca más bien, paralelo aún por estudiarse, la obra de José Martí, en el sentido de mayor sintonía con aquel ya mencionado - a contracorriente del elitismo modernista - ideal poetológico vallejiano; y, asimismo, el posicionamiento del sujeto allí: "Es justamente en la inmediatez y en su modo de entender la subjetividad donde se abre la brecha entre la poética martiana y la poética romántica, también cimentada en el yo, los sentidos y su relación con la naturaleza. Martí era romántico por su anhelo de absolutos y su fe en el porvenir, aunque más moderado [...] El yo que Martí anuncia como respuesta a la modernidad, a la crisis finisecular, no es confesional o personalizado: es un yo que quiere asumir en sí al universo, un yo colectivo que no expresa la individualidad sino el alma del mundo" (ROTKER, 1992, p.129).

10 "Es posible distinguir dos etapas o ciclos en el vasto conjunto de la escritura periodística de Vallejo. Una primera en la que todavía se perciben los signos de su juvenil impronta modernista, etapa caracterizada por el regusto de la palabra, la búsqueda del término exquisito y refinado, le mot rare; por ciertos toques impresionistas; por una nota lírica, introspectiva y una suerte de monólogo interior en el que aparece a ratos, curiosamente, la crónica mirándose a sí misma [¿¿Santa Teresa, Martí?]" (PUCCINELLI, 2002, p. XXXII). 
España - que lo enfrentan a un nuevo destinatario - modelaría una nueva escritura en sus crónicas, las cuales: "estilísticamente ingresan imperceptiblemente en el mismo espacio literario de sus Poemas en Prosa y de sus Poemas Humanos, de los que constituyen un texto paralelo. Vemos así como su juvenil preocupación por encontrar le mot rare es reemplazada por la búsqueda de le mot juste, impactado por sus lecturas de Joseph Conrad ["Dadme la palabra justa y el acento justo, y moveré el mundo"] [H1] (PUCCINELLI, 2002, p. XXXVIII).

Ahora, respecto a ilustrar cómo funciona $\mathrm{H} 3$ - en su dialéctica con $\mathrm{H} 1, \mathrm{H} 2$ y H4 - vamos a recurrir a lo que, según el semiólogo Enrique Ballón, luego de enfatizar el anticapitalismo económico y el repudio a la cultura burguesa por parte de nuestro cronista, caracteriza a estas crónicas:

el reparto temático en las crónicas de Vallejo presiente la tarea que R. Barthes asignaba a la revista literaria de hoy: ver el mundo tal como se hace a través de una conciencia literaria; considerar periódicamente la actualidad como el material de una obra secreta; es decir, para el enunciador, situarse en ese momento muy frágil y muy oscuro en el que la información de un hecho real va a ser captada por el sentido político y literario (BALLÓN, 1982, p. 92, subrayado nuestro).

Conciencia literaria, la que percibe Ballón aquí, la cual no es otra cosa que la noción de las humanidades como narrativas (H3); sumada a ésta, y en cuanto desencadenante aquí de un sentido político, también la noción de las humanidades a modo de pueblos $(\mathrm{H} 2)$.

De modo semejante, y para ir de una vez al análisis del tamizado del tema peruano, y de las posibilidades de la concurrencia allí de H4, recurrimos de nuevo a Enrique Ballón:

cuando José María Arguedas se refiere a Vallejo calificándolo de era el principio y el fin y lo anaforiza semánticamente como dios liberador, Aquel que se reintegra [El zorro de arriba, el zorro de abajo, Buenos Aires: Losada, 1975, p. 270], pone el acento semántico en restituir (rasgo de /reintegrar/) y no en componer (rasgo de /integrar/). Desde la perspectiva de Arguedas, el proyecto de Vallejo [en sus posiciones de madurez ${ }^{11}$ ] es, pues, la restitución de la faz singular (no particular) de la literalidad nacional a través de un sólido esfuerzo por adensar los valores literarios peruanos y, consecuentemente, la denuncia (o redargución) de la seudoidentidad oficial de la literatura peruana manipulada por la crítica nacional obsecuente (BALLÓN, 1982, p. 58).

Obviamente, tenemos aquí canon: se habla de obras literarias $(\mathrm{H} 1)$; pero, sobre todo, en la lectura de Ballón coinciden nuevamente $\mathrm{H} 3+\mathrm{H} 2$. Es decir, nación en tanto literaridad $(\mathrm{H} 3)$ más denuncia de la seudoidentidad de la crítica nacional $(\mathrm{H} 2)$. Y H4 todavía no aparece. Perspectiva, la de H4, que no atañe - aunque pueda implicarlo -

11 ¿Debemos entender aquí, Poemas humanos y España, aparta de mí este cáliz versus los inmaduros o irresponsables Los heraldos negros y Trilce? ¿Tungsteno, sí, y Una piedra cansado, no? ¿Colacho hermanos contra Dressing Room? En fin, podemos colegir que Ballón enarbola aquí al Vallejo marxista o más comprometido políticamente. 
a multiculturalismo ${ }^{12}$ o crítica política o cultural; sino, más bien, a una mirada finalmente ontológica. Noción post-antropocéntrica o simétrica; la cual, en términos del nuevo realismo sería - entre las otras tres nociones de las humanidades $(\mathrm{H} 1, \mathrm{H} 2$ y H3) - la única en poder quebrar el correlato (RAMIREZ, 2016, p. 40) ya que no hay sujeto propiamente dicho o éste ya no es únicamente humano, sino multinaturalista o post-humano (postantropocéntrico). Esto último, insistimos, una de las columnas vertebrales o donde se juega su propia posibilidad también el nuevo realismo:

La preeminencia de la ontología que plantea el nuevo realismo tiene implicaciones que cuestionan el acendrado antropocentrismo de la tradición filosófica. No se trataría de derivar de la nueva ontología un antihumanismo y menos un inhumanismo. Se trataría simplemente de abrirnos, quizá por primera vez en la historia del pensamiento, a una comprensión no-humana, a-humana, del ser y la existencia y, al fin, del propio ser humano (RAMIREZ, 2016, p. 41).

Las humanidades a modo de H4, en las crónicas de César Vallejo, se van perfilando desde muy temprano, poco a poco y cada vez más. Nítidamente, desde su propuesta de la creación artística en términos fisiológicos ${ }^{13}$ o naturales:

Satie no expresa esto ni aquello [...] En Satie se ve cómo la música llega a ser un arte tan alto y puro, libre e incondicionado, que deja ya de ser arte. Y quizás este es el gran camino: matar al arte a fuerza de libertarlo. Que nadie sea artista... Que el acto de emocionar sea un acto literalmente natural. Hacia allá iba Erick Satie [El más grande músico de Francia, 1926] (VALLEJO, 2002, t. I, p. 261).

O, desde su planteo - referido a la escultura, pero que podemos interpolar a la escritura - de la necesidad de un arte infracerebral: "potencia, sentimiento manual o sentido inocente [recordemos su manifiesto contra la voluntad indigenista] de la plástica, característico y decisivo en el escultor" (VALLEJO, 2002, t. II, p. 931). Y más temprano todavía, en tanto H4 como giro animal - en toda su poesía - y, entre otros, también en el cuento Los Caynas (Escalas melografiadas, 1923). Según Américo Ferrari:

12 "uno de los rasgos distintivos del pensamiento amerindio en relación con las cosmologías 'multiculturalistas' modernas; en tanto estas últimas se apoyan en la implicación mutua entre la unicidad de la naturaleza y la multiplicidad de las culturas [...] la concepción amerindia supondría, por el contrario, una unidad del espíritu y una diversidad de los cuerpos. La 'cultura' o el sujeto representaría la forma de lo universal, y la 'naturaleza' o el objeto la forma de lo particular" (VIVEIROS DE CASTRO, 2010, p.34).

13 Según, Bernat Padró Nieto: "La cuestión clave del arte y de la poesía nueva, dice Vallejo, es fisiológica. Por ello discute la dimensión elitista que pretendían darle ly en la que andaban errados, recuérdese el éxito del Cubismo] Ortega y Gasset o Guillermo de Torre, que consideraban el arte nuevo impopular porque la masa no lo entiende" (GRANADOS, 2016). Prejuicio que amerita el siguiente corolario de Padró: "La apuesta por la sensibilidad por encima de la forma y la convicción de la dimensión humana de un arte producido desde la sensibilidad, constituían una posición estética extraordinariamente moderna. Justamente esa dimensión humana podía hacer del arte y la literatura una actividad política" (GRANADOS, 2016). Ahora, un segundo corolario se amerita aquí: por la sensibilidad se accedería, paradójicamente, a otro nivel ontológico; y todavía un tercero: mito y concepto no se opondrían en Vallejo, sino que constituirían un andrógino (H4). En esto último el autor peruano sigue y enmienda la plana a lo que, en general, propone el nuevo realismo. 
'Los caynas' que narra un desdoblamiento colectivo de hombres monos, y 'Mirtho' ('Mi amada es 2') en Escalas de la época de Trilce, y los poemas 'Cuatro conciencias', 'Nómina de huesos' y 'Altura y pelos' [...] Cotéjese también el poema 'Tengo un miedo terrible de ser un animal', en el que el tema del desdoblamiento se cruza con el de la animalidad, como en 'Los caynas', que en 'A lo mejor, soy otro' parece expresarse en el verso 6 por la presencia del zorro [La representación del ser humano como un animal es una constante en la última etapa de la trayectoria poética de Vallejo] (FERRARI, 1996, p. 447).

Incluso podríamos decir que más que propiamente escribir, el autor de Trilce muda lo humano a un nuevo y mejor soporte - post-humano - y así conserva mejor aquello. Lo más parecido a su escritura, en la literatura peruana, es el pasaje dedicado al zumbayllu de la novela Los ríos profundos ${ }^{14}$, de José María Arguedas; el cual por ser trompo no sería menos, sino incluso mucho más humano.

En suma, pues, la elección y constancia del tema Perú (tema inca o incluso tema andino) en la obra de César Vallejo, y en particular en sus crónicas, coincide con su cada vez más patente postura ontológica y simultáneamente, podemos dar fe de ello ${ }^{15}$, también su rol como mediador conceptual. Si bien la visión y arte de Vallejo responde - tal como en Stravinsky o en Satie - a un mito inscrito en el paisaje ${ }^{16}$, en el caso de César Vallejo el mito de Inkarrí (GRANADOS, 2014; 2017); éste se trata - tal como lo apuntamos con aquello de seguir y enmendar la plana al nuevo realismo (nota 13) - en términos de conceptos, jamás de folklore. No es que con esto, pues, Vallejo procure escaparse de la realidad ni consolarse ante la catástrofe de la Guerra Civil Española ni refugiarse en una metafísica o religiosidad tradicional. Sino, y por el contrario, muy consciente de que el trabajo pendiente - hasta hoy mismo, sino fijémonos en los esfuerzos del nuevo realismo en rescatar la ontología de la predominante epistemología ${ }^{17}$ - consiste, respecto al tema incaico, en activar un campo de sentido, independiente de $\mathrm{H} 1, \mathrm{H} 2 \mathrm{o} \mathrm{H} 3$, al que vamos denominando Humanidades como simetría (H4). O más bien deberíamos, a estas alturas de nuestro ensayo, denominar humanidades como androginia de mito y concepto, o de razón - a partir de la sensibilidad - y no de inteligencia:

14 “Antero encordeló el trompo, lentamente, con una cuerda delgada; le dio muchas vueltas, envolviendo la púa desde su extremo afilado; luego lo arrojó. El trompo se detuvo un instante en el aire y cayó después en un extremo del círculo formado por los alumnos, donde había sol. Sobre la tierra suelta, su larga púa trazó líneas redondas, se revolvió lanzando ráfagas de aire por sus cuatro ojos; vibró como un gran insecto cantador, luego se inclinó volcándose sobre el eje. Una sombra gris aureolaba su cabeza giradora, un círculo negro lo partía por el centro de la esfera. Y su agudo canto brotaba de esa franja oscura. Eran los ojos del trompo, los cuatro ojos grandes que se hundían, como en un líquido, en la dura esfera" (ARGUEDAS, 1983, p. 65-6).

15 Lo comprobamos en la UFAC (Rio Branco, Acre, Brasil, junio 5-9, 2017). Sobre todo, cuando propusimos poner en paralelo, en el aula, nuestras lecturas autobiográficas o auto-ficcionales de Borges y yo (El hacedor, 1960) y Huaco (Los heraldos negros, 1918). A través de este ejercicio fue patente ver cómo tenemos en la poesía del peruano una alternativa al giro lingüístico que representaría la obra de Jorge Luis Borges.

16 "Así han hecho Stravinsky, a base de la estepa rusa y el francés Satie, a base de piedras druídicas [La historia de América, 1926]" (VALLEJO, 2002 I, p. 224) [H 4].

17 "[Harman] Sostiene que la epistemología es en sí misma una forma poco convincente de ontología, pues asume que la relación humano-mundo posee un estatus ontológico central en el cosmos que otras relaciones no poseen" (RALÓN, 2016, p.234). 
‘'no he de transigir nunca con Ud. [Vicente Huidobro]. En la excesiva importancia que Ud. da a la inteligencia en la vida. Mis votos son siempre por la sensibilidad'. Para él [Vallejo] lo esencial es la sensibilidad y por eso en la polémica con el indigenismo en materia de arte americano él le concede primacía a la sensibilidad indígena sobre la voluntad indigenista [o antropológica o, si no, de algún purismo lingüístico, agregaríamos] (VALLEJO, 2002, t. I, p. 182).

De modo muy significativo, nuevo realismo y multinaturalismo $(\mathrm{H} 4)$ coinciden en este punto. Por ejemplo, mientras Mauricio Ferraris encuentra en la estética, entendida como una teoría de la sensibilidad, la percepción y la sensación, el fundamento de una ontología, pues, claramente, la percepción no da acceso a algo que no puede reducirse a la representación o imagen que podemos tener de ello (RAMÍREZ, 2016, p. 24); Pedro Reygadas, por su parte, lo elabora así:

el ethos originario amerindio ponía lo estético en el fundamento de lo ético y lo ético en el fundamento de lo lógico; con las emociones al centro de lo humano. En el mundo indoamericano, desde el perspectivismo amazónico que dota de agencia a los seres que Occidente considera no-humanos hasta el Norte continental, la dimensión estética es crucial (REYGADAS, 2010, p. 231).

Inkarrí, sin alienar su estatuto canónico, libro valioso para una comunidad cultural concreta (pan andina), ni dejar de ser finalmente un relato, apunta por último a otra cosa. A alentar la constitución de una comunidad - o archipiélago solar - sin fronteras y, por lo tanto, también a difundir una ética vinculada a un dios por venir; análogo al que nos presenta Quentin Meillassoux a través de su crítica a la filosofía de la inmanencia de Deleuze, de ascendencia spinoziana y bersogniana ${ }^{18}$ : "el limitar la inmanencia a este mundo y el no pensar en la posibilidad de un ultramundo donde la inmanencia sería completa y sin defecto [lo cual implicará] la extraña idea de un Dios inmanente o un Dios virtual" (RAMÍREZ 2016, p., 197). En otras palabras, e interpolando, pasaríamos también aquí de un Inkarrí traducido de lo étnico a un concepto, aquel Dios virtual del nuevo realismo ${ }^{19}$. Y, no menos, pasaríamos a cierta noción de la ética, tentativamente vallejiana o simétrica o amerindia, pero afirmativamente nuevo realista. Dice Bennet:

18 "Dios se expresa en todas las cosas y todas las cosas expresan a Dios. No hay más trascendencia [o sus sucedáneos modernos: la conciencia, la razón, las leyes de la naturaleza o de la historia, el superyó, etc.], el Ser es uno (unívoco), absoluto (expresivo) y eterno (inmanente)" (RAMíREZ, 2016, p.194).

19 Ambos, el de Vallejo y el de Meillassoux, un Dios un tanto judío. No tenemos datos sobre el francés; pero el supuesto judaísmo de César Vallejo ya ha sido inicialmente ventilado, al menos en la ficción: "la irrefutable evidencia del ancestro judío de Vallejo se encuentra, según Ángel, en su misma vida y obra: siempre lo acompañó una sed religiosa a modo de los profetas bíblicos, en intimidad con un Dios vivo, y no con un Dios dogma; siempre anidó un pensamiento político que privilegia el amor al prójimo, la justicia social, el sufrimiento redentor del inocente, la esperanza apocalíptica encarnada en el Mesías. ¿Y cuáles son las 'cualidades típicas' judías que revela su obra? Según Ángel: el amor al pueblo; el deseo de asumir toda la cultura universal; el gusto por las alusiones bíblicas, la importancia asumida al simbolismo numérico, con ecos de la Cábala; and last, but not least, la concepción de Jesús como heredero fidedigno de los profetas bíblicos. Ahora bien, la prueba decisiva que Ángel necesita la carta genealógica materna de uno de sus abuelos curas - , yace en una de las salas cavernosas de la Jewish Division de la Bilioteca Pública de New York, en Manhattan" (GOLDEMBERG, 2001). 
La consecuencia, para Bennett, es que ya no puede sostenerse una ética de la culpa, o un moralismo del culpable. Cada evento es un agenciamiento único de diversos actores, cada cuerpo es un conglomerado, un agregado de otros protocuerpos [de corte spinozista en tanto cuerpos conativos o asociativos; y modos de una sustancia común $]^{20}$. Bennett sostiene a su vez un monismo inmanente, pero en lugar de asignar a Dios la sustancialidad única de cuyos modos emanarían las entidades particulares, piensa más bien en una única sustancia en proceso, la materia viviente (FLORES, 2016, p. 275).

Materia viviente (Inkarrí) en su metáfora solar, agregaríamos nosotros: el sol sale para todos y todos tenemos semejantes derechos y obligaciones. Todos, no una etnia ni una lengua ni, tampoco, una nacionalidad particular. Todos a manera de una radical constatación de nuestra complementariedad y auspicio de la conjunción. Todos a manera de experiencia común y de gozo frente a la noria de la duda o el nihilismo (modernismo, surrealismo, indigenismo) que jamás compartió César Vallejo. Y fe y militancia - finalmente en el mestizaje - en los que pareciera sí osciló, infelizmente y a contrapelo, José María Arguedas, aquel de "Vallejo era el principio y el fin". Es decir, Arguedas osciló entre antropocentrismo y post-antropocentrismo (entre $\mathrm{H} 2$ y $\mathrm{H} 4$ ), no se las jugó conceptualmente del todo por esto último; parcializó o esencializó en términos culturales - con beneplácito general de la crítica - y acaso esto mismo también desencadenó su abrupta partida.

\section{Conclusión}

Las expediciones europeas que, después de la época misma de la dominación española, se han sucedido en el país de los Incas, han sido sobre todo de orden arqueológico [...] contienen conclusiones bastante completas que pueden servir de base para la elaboración de la ciencia prehistórica americana (VALLEJO, 2002, t. II, p. 950).

Vallejo, al referirse al "país de los Incas", está pensando en un legado de América toda para el mundo. Y observa la ciencia de la arqueología como un paso previo, una "base", para otra tarea que él denomina aquí "ciencia prehistórica americana". Es decir, esta última "ciencia", respecto a la anterior, no sería la misma; sino algo, diríamos, cualitativo o más profundo o más íntimo. Algo que hemos ido vinculando aquí, aunque sin que Vallejo lo elabore en estos términos, con la ontología que propone el nuevo realismo. Los resultados, sino sólo sugerentes, creemos podrían pasar a constituirse en auspiciosos. Asimismo, y como punto de partida en este ensayo sobre la labor periodística vallejiana, y en tanto

20 Conceptos plasmados en un autorretrato tardío de Paul Gauguin (Camino del Gólgota) pintor del cual Vallejo en un debate de la época sobre si aquél era peruano o francés - enarbolaba: "Gauguin [el hijo de Flora Tristán] es, por todos respectos, una sensibilidad peruana [...] Los amores temáticos del gran pintor, su fuerza temeraria, su exceso insultante, su simplicidad, están voceando los Andes, el Amazonas, el Cuzco" (VALLEJO, 2002, t. I, p. 357, subrayado nuestro). Aquella sensibilidad, entonces, aunque tenga un entronque cultural $(\mathrm{H} 2)$ es ya sin fronteras étnicas y pasa a constituir un rasgo ontológico, entre otros, universal $(\mathrm{H} 4)$. 
y en cuanto un proyecto de taxonomía cualitativa de la misma, hemos comenzado por situar sus crónicas en determinados campos de sentido a los que hemos denominado Humanidades (libros, pueblos, narrativas o post-antropocentrismo). Proceder de esta manera nos ha permitido observar la dinámica conceptual, sino ontológica, que subyace en las crónicas vallejianas; en particular, las agrupadas bajo el tema andino o peruano. Y comprobar que el interés del autor sobre el mismo no fue tardío, sino una constante. Y lo que cambió fue, solamente, un tanto la asiduidad. Hacer coincidir, entre sus crónicas, varios, o el total, y más nítidos campos de sentido. Es decir, ya no sólo las humanidades a modo de libros $(\mathrm{H} 1)$, pueblos $(\mathrm{H} 2)$ o narrativas $(\mathrm{H} 3)$, sino lo que compete también -de modo decisivo y como aporte a la cronística americana incluso del futuro - a la simetría o post-antropocentrismo $(\mathrm{H} 4)$.

Pedro J. Granados es Ph.D (Hispanic Language and Literatures) por Boston University, Master of Arts por Brown University; y bachiller en Humanidades por Pontificia Universidad Católica del Perú. Es especialista en la obra de César Vallejo. El 2016, con Trilce/Teatro: guión, personajes y público, mereció el Prêmio Mario González de la Associação Brasileira de Hispanistas (ABH). Actual docente en la UNMSM. Desde el 2014 preside el Vallejo sin Fronteras Instituto (VASINFIN).

pedro_granados@hotmail.com

\section{Referencias}

ARGUEDAS, J. M. Relatos completos. Madrid: Alianza Editorial, 1983.

BALLÓN, E. La escritura poetológica: César Vallejo, cronista. Lexis, vol. 6, n. 1, 1982, p. 57-98.

CHANG RODRíGUEZ, E. Las crónicas posmodernistas de César Vallejo. Inti, vol. 1, n. 36, 1992, p. 11-22.

CHARTIER, R. La historia o la lectura del tiempo. Barcelona: Gedisa, 2007.

FERRARI, A. Poesía completa de César Vallejo. Madrid: Archivos, 1996.

FLORES PEÑA, G. R. En la estela del realismo especulativo. In: RAMÍREZ, M. T. (org.). El nuevo realismo: La filosofía del siglo XXI. México: Siglo XXI Editores, 2016, p. 250-277.

GABRIEL, M. Por qué el mundo no existe. In: RAMÍREZ, M. T. (org.). El nuevo realismo: La filosofía del siglo XXI. México: Siglo XXI Editores, 2016, p. 151-169.

GOLDEMBERG, I. Los pronombres reflexivos. In: Congresso Internacional de la Lengua Española, II, 2001, Valladolid. Cervantes.es. Disponível em: http://congresosdelalengua.es/valladolid/ponencias/ unidad_diversidad_del_espanol/3_el_espanol_en_los_EEUU/goldemberg_i.htm. Acesso em: 4 out. 2019. 
GONZÁLEZ ECHEVARRÍA, R. Mito y Archivo. Una teoría de la narrativa Latinoamericana. México: FCE, 2012.

GONZÁLEZ MONTES, A. DavidSobrevilla, César Vallejo. Poeta nacional y universal y otros trabajos vallejianos. Revista Lexis, vol.19, n.1 Lima: Amaru Editores, 1995, p. 237-243.

GRANADOS, P. Trilce/Teatro: guión, personajes y público. Brasil: ABH, 2017.

. Reseñas de las Actas del Congreso Internacional Vallejo Siempre, Montevideo, 2016. Vallejo sin Fronteras, mai. 2016. Disponível em: http://vallejosinfronteras.blogspot.com/2016/05/resenas-delas-actas-del-congreso_51.html. Acesso em: 4 out. 2019.

Trilce: húmeros para bailar. Lima: VASINFIN, 2014.

HELBO, A. El teatro. ¿Texto o espectáculo vivo? Buenos Aires: Galerna, 2012.

NIETZSCHE, F. Fragmentos póstumos, Tecnos. Madrid, 2008. Traducción Juan Luis Vermal - Joan. B. Llinares. p.60.

PESSOA, F. Poemas de Ricardo Reis. (Edição Crítica de Luiz Fagundes Duarte.) Lisboa: Imprensa Nacional - Casa da Moeda, 1994.

PIGLIA, R. Crítica y ficción. Buenos Aires: Seix Barral, 2000.

PUCCINELLI, J. Estudio preliminar. In: VALLEJO, C. Artículos y crónicas completos, I. Lima: PUCP, 2002, p. XV-LXXI.

RALÓN, L. Hacia una nueva cuaternidad: Graham Harman y la ontología orientada a objetos. In: RAMÍREZ, M. T. (org.). El nuevo realismo: La filosofía del siglo XXI. México: Siglo XXI Editores, 2016, p. 211-236.

RAMÍREZ, M. T. (org.). El nuevo realismo: La filosofía del siglo XXI. México: Siglo XXI Editores, 2016.

REYGADAS, P. El arte de argumentar: una visión del ethos desde América Latina. In: CARRETERO, F. L. (org.). Introducción a la teoría de la argumentación. Guadalajara: Editorial Universitaria/ Universidad de Guadalajara, 2010, p. 228-240.

RIZO-PATRÓN, R. Multinaturalismo e interculturalidad en el horizonte del mundo de la vida. In: Anuario colombiano de fenomenología, volumen VII, Pereira, Co.: Universidad Tecnológica de Pereira/Editorial UTP. Vol. I, pp.195-209.

ROTKER, S. La invención de la crónica. Buenos Aires: Ediciones Letra Buena, 1992.

VALLEJO, C. Artículos y crónicas completos, I y II. Edição: Jorge Puccinelli. Lima: PUCP, 2002.

Teatro Completo I. Edição: R. Silva-Santisteban y Cecilia Moreano. Lima: PUCP, 1999.

VIVEIROS DE CASTRO, E. Metafísicas caníbales: Líneas de antropologia postestructural. Madrid: Katz Editores, 2010.

WITTGENSTEIN, L. Investigaciones Filosóficas. Traducción del original alemán, introducción y notas de Jesús Padilla Gálvez. Editorial Trotta, Madrid, 2017. p. 329 